\title{
The Morphology of Nano-MgO Particles Induced by Attapulgite
}

\author{
Pan Meiling \\ School of Chemistry and Chemical \\ Engineering, Southeast University, \\ Nanjing, China
}

\author{
Zhou Li \\ School of Chemistry and Chemical \\ Engineering, Southeast University, \\ Nanjing, China
}

\author{
Wang Yihong* \\ School of Chemistry and Chemical \\ Engineering, Southeast University, \\ Nanjing, China, 15951075627 \\ yihongwang@seu.edu.cn
}

\begin{abstract}
In this paper, a new way to prepare controlled nanoMgO with different morphology facilely by using modified attapulgite as hard template was found. The morphology details were investigated by scanning electron microscopy (SEM). It was found that the morphology of nano-MgO particles was induced by the ratio of attapulgite versus $\mathrm{Mg}^{2+}$. The lamella morphology of $\mathrm{MgO}$ was converted to sphere particles, then the rod-like and needle-like or fiber-like shape, while the content of attapulgite was raised.
\end{abstract}

\section{Keywords- nano-MgO; Attapulgite; crystallite}

\section{INTRODUCTION}

Nano magnesium oxide (nano- $\mathrm{MgO}$ ) is an exceptionally functional materials that have been widely used in catalysts ${ }^{[1]}$, superconductors ${ }^{[2]}$, anti-bacterial materials ${ }^{[3]}$, and so on. Several shapes and sizes nano-MgO particles were synthesized, such as nanosphere, nanocube and nanorod. What the magnesium salts, precipitant were used, and the reaction conditions play an important role on the shapes and sizes of nano-MgO particles. The most conventional method for preparation of nano- $\mathrm{MgO}$ is depositing different magnesium salts or magnesium hydroxide at first ${ }^{[4,5]}$, magnesium precursors and solvents as the reactants, $\operatorname{Mg}(\mathrm{OH})_{2}$ nanocrystallines with rod-, tube-, needle-, or lamella-like morphologies by a hydrothermal reaction were obtained ${ }^{[6]}$, which was very important for the morphological features of subsequent nano-MgO particles by thermal decomposition.

The physical and chemical properties of Nano-MgO crystallites are directly connected with their sizes, shapes and size dispersion, therefore a new and inexpensive method to synthesize nano-MgO with narrow size distribution, controllable structure and morphology, and large specific surface area is necessary. Generally, one-dimensional nanostructures can be fabricated by template-directed growth methods. Attapulgite(ATP, or palygorskite) clay, a species of hydrated magnesium aluminum silicate mineral with commonly a rod-like or fibrous morphology, is a natural nanostructural material with an ideal formula $\mathrm{Si}_{8} \mathrm{O}_{20}(\mathrm{Mg}, \mathrm{Al}$, $\mathrm{Fe})_{5}(\mathrm{OH})_{2}\left(\mathrm{OH}_{2}\right)_{4}{ }_{4} \mathrm{H}_{2} \mathrm{O}$. It is characterized by a porous crystalline structure containing tetrahedral layers alloyed together along longitudinal sideline chains ${ }^{[7]}$. Octahedral units of $\mathrm{MgO}$ positioned parallel to these corrugations produce open ended (but otherwise enclosed) rectangular channels,

This research work was supported by Science and technology support program of Jiangsu Province BE2010721 equivalent to about one amphibole unit wide $(0.6 \mathrm{~nm})$ and one brucite unit high $(0.37 \mathrm{~nm})^{[8]}$. Due to its regular structure and large specific surface area, considerable porosity, and thermal stability, ATP has been used as absorbent ${ }^{[9]}$, catalyst and catalyst support ${ }^{[10,11]}$. However, there have few reports published, up to date, with respect to the abrication of oxide nano-structure templated by attapulgite.

To make the synthetic approach more convenient, much effort has been made for nano-structure materials. Anodic alumina membrane ${ }^{[12]}$ and $\mathrm{CNTs}$ or $\mathrm{TiO}_{2}$ are often used hard template ${ }^{[13]}$. Several soft colloidal templates such as anionic sodium dodecylsulphate(SDS) and the cationic cetyltrimethylammonium chloride (CTAC) or bromide(CTAB) also play an important role in controlling the size and shape of inorganic nanocrystals ${ }^{[14]}$. In this contribution, we firstly report an efficient method to synthesis nano- $\mathrm{MgO}$ with different morphology using natural attapulgite as hard template.

\section{EXPERIMENT}

The attapulgite was obtained from Jiangsu Jiuchuan Nami Material Technology Co., Ltd with purity more than $90 \%$, and further purified by $3 \mathrm{M}$ solution of $\mathrm{HCl}$ for $3 \mathrm{~h}$ under $75^{\circ} \mathrm{C}$, washed ATP with distilled water until the chloride was not detected, dried and reserved. All other chemicals used in this work, such as $\mathrm{Mg}\left(\mathrm{NO}_{3}\right)_{2} \bullet 6 \mathrm{H}_{2} \mathrm{O}$ and urea were A.R. grade reagents.

Nano-MgO particles were prepared by homogeneous precipitation method: firstly the $\mathrm{Mg}\left(\mathrm{NO}_{3}\right)_{2} \cdot 6 \mathrm{H}_{2} \mathrm{O}$ was dissolved in water at $95^{\circ} \mathrm{C}$ under vigorous stirring to form a transparent solution. Then urea solution was added dropwise under strong stirring at the mole ratio 1:5 of magnesium ion to urea $\left(\mathrm{Mg}^{2+} /\right.$ urea $)$. The $\mathrm{Mg}(\mathrm{OH})_{2}$ precursor was generated and the resultant suspension was continuously stirred for $3 \mathrm{~h}$. After precipitation, the mixture was cooled to room temperature, filtered, ultrasonic washed with deionized water and absolute ethanol several times for an effective removal of $\mathrm{NO}_{3}{ }^{-}$ion and the better dispersion of $\mathrm{Mg}(\mathrm{OH})_{2}$ precipitation, which was dried at $80^{\circ} \mathrm{C}$ for $4 \mathrm{~h}$ and calcined at $420^{\circ} \mathrm{C}$ for $2 \mathrm{~h}$.

$\mathrm{MgO} \mathrm{NPs} / \mathrm{ATP}$ were prepared by mixing $\mathrm{Mg}\left(\mathrm{NO}_{3}\right)_{2}$ aqueous resolution and ATP, $\mathrm{Mg}^{2+}$ went into ATP channel by ion exchange, then $\mathrm{Mg}(\mathrm{OH})_{2}$ was deposited homogeneously on the ATP by adding urea. The reactions were as follows:, 
$\mathrm{Mg}\left(\mathrm{NO}_{3}\right)_{2} \bullet 6 \mathrm{H}_{2} \mathrm{O}$ was dispersed in distilled water and stirred in a three nicked flask for $5 \mathrm{~min}$, then the ATP were added in the suspension. The mixed solution was kept at $80^{\circ} \mathrm{C}$ for $3 \mathrm{~h}$ with stirring, followed by urea adding. The mixture was continually stirred for 20-40 min and then rise the temperature to $95{ }^{\circ} \mathrm{C}$ for $3 \mathrm{~h}$, filtered, ultrasonic washed with deionized water and absolute ethanol several times, dried and calcined. The ATP can be removed by treating $\mathrm{MgO} / \mathrm{ATP}$ mixture several times with $2 \mathrm{~mol} / \mathrm{L} \mathrm{NaOH}$ solution at $80{ }^{\circ} \mathrm{C}$ for $30 \mathrm{~min}$.

Thermal behavior of $\mathrm{MgO} / \mathrm{ATP}$ mixture was studied on the Thermo Gravimetric Analysis (TGA) PerkinElmer TGA-7). Specimens were put in a platinum crucible and heated at a rate of $10.00 \mathrm{~K} / \mathrm{min}$ from $50^{\circ} \mathrm{C}$ to $800^{\circ} \mathrm{C}$ in $\mathrm{N}_{2}$ flow. Morphology and structure were observed on scanning electron microscope (SEM) with Ultra Plus field-emission (Germany Zeiss Co., Ltd) operating at $10 \mathrm{kV}$.

\section{RESULTS}

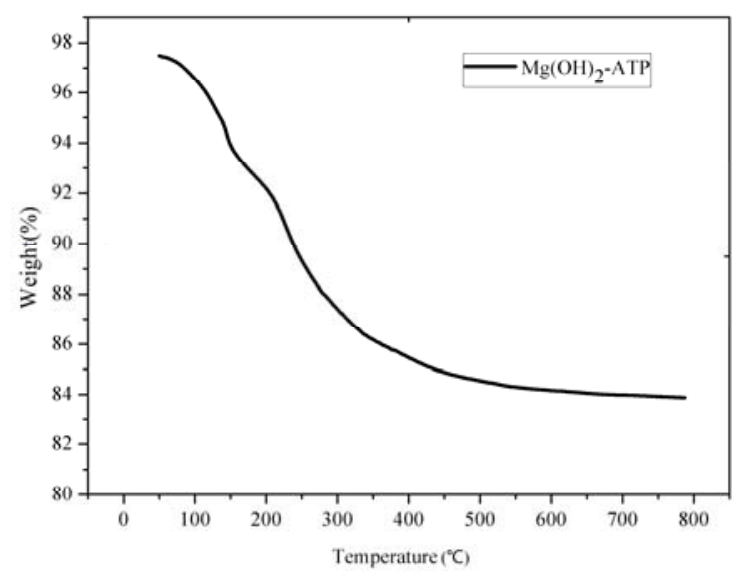

Figure 1. TGA curves obtained in $\mathrm{N}_{2}$ flow for $\mathrm{Mg}(\mathrm{OH})_{2} / \mathrm{ATP}$ nanocomposite

The TGA technique was used to analyze the thermal behavior of the $\mathrm{MgO} / \mathrm{ATP}(\mathrm{ATP}$ amount $=90 \%$ ) and thus could provide the necessary data for the following decomposition process. The mass loss curves for $\mathrm{MgO} / \mathrm{ATP}$ composites are shown in Figure 1. For the MgO/ATP composites, the weight loss happened mainly below $250^{\circ} \mathrm{C}$, which is similar to that of pure ATP, the weight losses below $120{ }^{\circ} \mathrm{C}$, and between $120^{\circ} \mathrm{C}$ and $230^{\circ} \mathrm{C}$ are the release of free water and adsorbed water of ATP respectively. And the one between $230^{\circ} \mathrm{C}$ and $330{ }^{\circ} \mathrm{C}$ can be attributed to the removal of crystal water of ATP. The one from $330{ }^{\circ} \mathrm{C}$ to $500{ }^{\circ} \mathrm{C}$ should be the decomposition of $\mathrm{Mg}(\mathrm{OH})_{2}$ to $\mathrm{MgO}$ and the release of the structural water of ATP, which was the basis that we choose $420{ }^{\circ} \mathrm{C}$ as calcination temperature of the samples, at $420{ }^{\circ} \mathrm{C}$, the magnesium hydroxide can decompose completely and the structure of ATP clay can be protected from damage.

Figure 2a shows the homogeneous morphologies of nano$\mathrm{Mg}(\mathrm{OH})_{2}$ particles with narrow size distributions and thus was chosen to undergo a subsequent calcination process to obtain $\mathrm{MgO}$ nano-crystals. From SEM images(shown in Figure 2a), it can be seen that the $\mathrm{Mg}(\mathrm{OH})_{2}$ precursors display the lamellar shape, the crystals of precursor was randomly piled up and presented a thin platelet shape, the thickness about 30 40nm and the lateral size about $500 \mathrm{~nm} \sim 1 \mu \mathrm{m}$, with a more or less circular contour. Moreover, the $\mathrm{Mg}(\mathrm{OH})_{2}$ precursor crystallite exhibits a smooth surface morphology(as shown in Figure $2 b$ ).

In order to make sure the effects about the amount of ATP on the shapes and sizes of $\mathrm{MgO}$ nanoparticles, four ratio of $\mathrm{MgO} / \mathrm{ATP}$ were chosen to prepare $\mathrm{MgO}$ nanoparticles and did some ananlysis (1) $0 \mathrm{wt} \%$; (2) $3 \mathrm{wt} \%$; (3) $25 \mathrm{wt} \%$; (4) $50 \mathrm{wt} \%$. (see Figure 3).

The amount of ATP strongly affected the size and morphological features of the resulting $\mathrm{MgO}$ particles. It was found that when the ATP was absent, the $\mathrm{MgO}$ powders retained the plate-like features of $\mathrm{Mg}(\mathrm{OH})_{2}$ precursor, the width of the lamellar powders is about $500 \sim 600 \mathrm{~nm}$ and the thickness of the plate is about $30 \sim 40 \mathrm{~nm}$. After it was calcined, the $\mathrm{MgO}$ crystallite exhibits a coarse surface compared to its original $\mathrm{Mg}(\mathrm{OH})_{2}$ precursor(as shown in figure $2 \mathrm{~b}$ ). A higher magnification SEM image (figure3-1) shows that the coarse morphology platelets are composed of nano-crystals with average crystallite size in $10 \sim 15 \mathrm{~nm}$ connected each other. When the content of ATP is $3 \%$, the MgO crystallite is still lamella morphology but the size of nano-crystals is increased to 20 25nm (as shown in Figure 3-2).

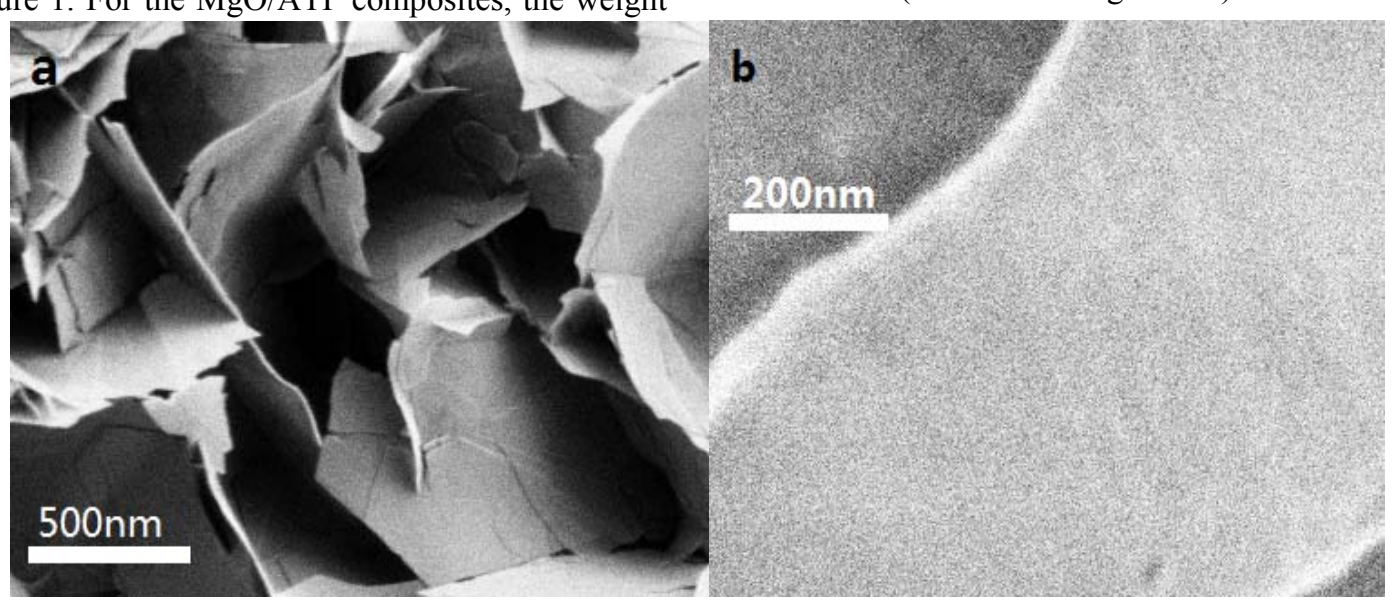

Figure 2. SEM images of the $\mathrm{Mg}(\mathrm{OH})_{2}$ precursor at a low magnification(a) and at high magnification (b) 


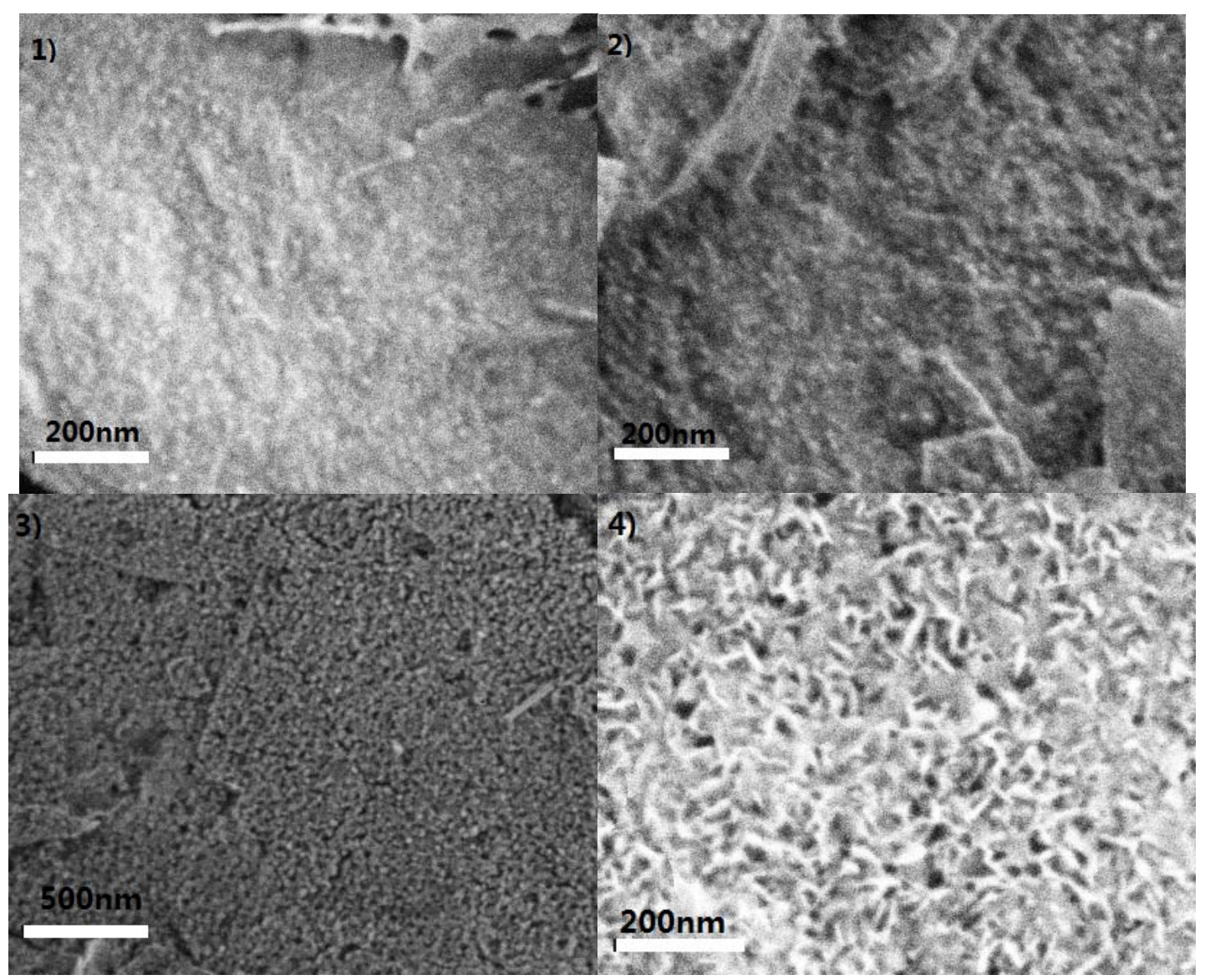

Figure 3. SEM images of MgO nanoparticles, 1) ATP amount=0; 2) ATP amount=3\%; 3) ATP amount=25\%; 4) ATP amount=50\%

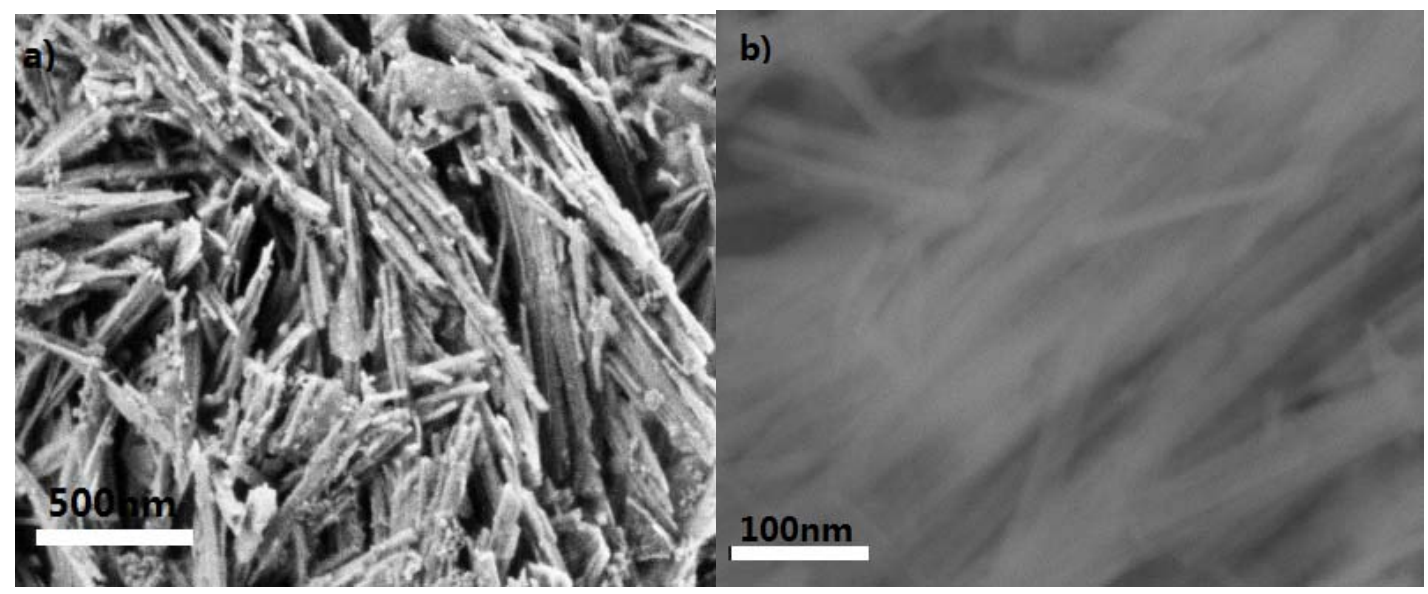

Figure 4. SEM images of MgO/ATP composites, a) ATP amount $=25 \%$; b) ATP amount $=90 \%$

Furthermore, it was found that the crystallite size of the synthesized $\mathrm{MgO}$ particles rises with the increase of the ATP contents. When ATP rise to $25 \%$, the crystal size becomes about $60 \sim 70 \mathrm{~nm}$, and plate-like particles begin to divide into spherical particles as shown in Figure3-3. When the ATP contents is $50 \%$, the rod-like or needle-like shaped morphology of the $\mathrm{MgO}$ particles was formed (Figure3-4). The needle's size was of $80 \sim 100 \mathrm{~nm}$ in length, on an average,
$10 \sim 15 \mathrm{~nm}$ in width. The morphological feature and the size of nano-MgO particles have undergone a significant change while ATP content was changed .

The morphology of the pure ATP is a 1-D fibrous shape with a uniform diameter ranging from 20 to $40 \mathrm{~nm}$, and the length ranges from 0.5 to $2 \mu \mathrm{m}$. The nano-MgO/ATP specimens were illustrated in Figure 4. As we can see in Figure 4.-a), nano-MgO NPs was uniformly deposited on the surface 
of ATP, it is further confirmed that when the content of ATP was about $25 \%$, the morphology of nano- $\mathrm{MgO}$ particles were sphere shapes, the template effected seems little. when the ATP content was $90 \%$, As show in Figure 4.-b) crystals of nano-MgO tended to become rod-like or needle-like shape, and grow on the attapulgite fiber very similar with the work about $\mathrm{CeO}_{2}$ nanotubes facilely via a layer-by-layer deposition approach using modified attapulgite as hard template, a simple and inexpensive way to prepare oxide nanotubes on a large scale by taking advantage of natural clay as sacrificial template $^{[12]}$. In this paper, during the process of form of $\mathrm{MgO}$, ATP clay doubtless plays an important role on its size and shape. The formation of $\mathrm{MgO}$ consists of two process, one is the thermal decomposition of $\mathrm{Mg}(\mathrm{OH})_{2}$, another is crystal transformation from $\mathrm{Mg}(\mathrm{OH})_{2}$ to $\mathrm{MgO}$ polycrystalline which is a amorphous process, and attapulgite maybe directly affect the change of crystal. And more, the ATP template effect is getting stronger with the increase of ATP in the form of $\mathrm{MgO}$, but the reason why the morphology of nano- $\mathrm{MgO}$ particles are changed from sphere shapes to rod-like or needle-like shapes with the increasing of ATP content is not clear, it needs further research.

\section{CONCLUSION}

In this paper, Size and feature controlled nano- $\mathrm{MgO}$ were synthesized successfully by using ATP as hard template. The content of ATP affects the shape and the size of nano-MgO crystals. It was a new way to obtain $\mathrm{MgO}$ with different morphology. ATP can be used as template to prepare massively nano-MgO crystallites of different size and morphology controlled, which is firstly reported. It needs more research in the aspect of induction mechanism and industrial applications.

\section{REFERENCES}

[1] B.Q. Xu, J.M. Wei, H.Y. Wang, K.Q. Sun, Q.M. Zhu., Nano-MgO: novel preparation and application as support of $\mathrm{Ni}$ catalyst for $\mathrm{CO}_{2}$ reforming of methane., Catal. Today., 2001, 68, pp.217-225
[2] Q.Z. Shi, Y.C. Liu, Z.M. Gao, Q. Zhao., Formation of MgO whiskers on the surface of bulk $\mathrm{MgB}_{2}$ superconductors during in situ sintering., J. Mater. Sci., 2008, pp.1438-1443

[3] L. Huang, D.Q Li., Y.J. Lin., M. Wei, D.G. Evans, X. Duan., Controllable preparation of Nano-MgO and investigation of its bactericidal properties., J. Inorg. Biochem. , 2005, pp. 986-993

[4] N. Sutradhar, A. Sinhamahapatra, B. Roy, H.C. Bajaj, I. Mukhopadhyay, A.B. Panda., Preparation of $\mathrm{MgO}$ nano-rods with strong catalytic activity via hydrated basic magnesium carbonates., Mater. Res. Bull. 2011, 46, pp. 2163-2167

[5] M.S. Mel'gunov, V.B. Fenelonov, E.A. Mel'gunova, A.F. Bedilo, K.J. Klabunde., Textural changes during topochemical decomposition of nanocrystalline $\mathrm{Mg}(\mathrm{OH})_{2}$ to $\mathrm{MgO}$., J. Phys. Chem. B., 2003, 107, pp. 2427-2434

[6] Y. Ding, G.T. Zhang, H. Wu, B. Hai, L.B. Wang, Y.T. Qian., Nanoscale Magnesium Hydroxide and Magnesium Oxide Powders: Control over Size, Shape, and Structure via Hydrothermal Synthesis., Chem. Mater. 2001, 13, pp. 435-440

[7] W.F. Bradley., The structural scheme of attapulgite., Am. Miner, 1940, 25 , pp.405-410

[8] P. Ni, J. Li, J.S. Suo, S. Li., Study on mechanical properties of polyurethane-attapulgite nanocomposites., J. Mater. Sci., 2004, 39, pp.4671-4673.

[9] L.F. Chen, H.W. Liang, Y. Lu, C.H. Cui, S.H. Yu., Synthesis of an attapulgite clay carbon nanocomposite adsorbent by a hydrothermal carbonization process and their application in the removal of toxic metal ions from water., Langmuir., 2011, 27, pp.8998-9004

[10] D.M. Araújo Melo, J.A.C. Ruiz, M.A.F. Melo, E.V. Sobrinho, A.E. Martinelli., Preparation and characterization of lanthanum palygorskite clays as acid catalysts., J. Alloy. Compd., 2002, 344, pp.352-355

[11] J.L. Cao, G.S. Shao, Y. Wang, Y.P. Liu, Z.Y. Yuan., CuO catalysts supported on attapulgite clay for low-temperature $\mathrm{CO}$ oxidation., Catal. Commun., 2008, 9, pp. 2555-2559

[12] K.L. Yu, G.L. Ruan, Y.H. Ben, J. Zou., Convenient synthesis of $\mathrm{CeO}_{2}$ nanotubes.,J.Mater.Sci.Eng.B,2007,139:197.

[13] A.G. Swartz, J. J. I. Wong, I.V. Pinchuk, R. K. Kawakami., $\mathrm{TiO}_{2}$ as an electrostatic template for epitaxial growth of $\mathrm{EuO}$ on $\mathrm{MgO}(001)$ by reactive molecular beam epitaxy., Journal of Applied Physcis.,2012,111

[14] M.P. PILENI, The role of soft colloidal templates in controlling the size and shape of inorganic nanocrystals., Nature Materials., 2003, 2, pp. 145-150

[15] Z.G. Chen, F. Chen, X.Z. Li, X.W. Lu, C.Y. Ni, X.B. Zhao., Facile synthesis of $\mathrm{CeO} 2$ nanotubes templated by modified attapulgite., J Rare Earth., 2010, 28, pp.566 570 